\title{
What's in an Ecology? A Review of Artifact, Communicative, Device and Information Ecologies
}

\author{
PETER LYLE, HENRIK KORSGAARD, and SUSANNE BØDKER, Aarhus University, Denmark
}

Decades of research have examined human-computer interaction with or across multiple (computational) artifacts as artifact ecologies, communicative ecologies, device ecologies, information ecologies, and other related conceptualisations. Although rich on observations and concepts, the works are largely self-contained and focused on using and developing concepts internally, with little ambitions toward synthesizing and strengthening what we know about these different theoretical concepts. In this paper we take stock of the literature on ecologies et al. in $\mathrm{HCI}$ and $\mathrm{CSCW}$ with the aim of identifying key positions, differences, similarities, and sub-concepts, as well as opportunities moving forward. From a reviewed corpus of 129 publications we consolidate 54 concepts into four influential positions and identify cross-cutting themes, conceptual gaps and challenges moving forward. In addition, we discuss issues related to the disconnected nature and theoretical quality of the concepts and how that impacts implicit theorising within our research community.

CCS Concepts: • Human-centered computing $\rightarrow$ HCI theory, concepts and models; Interaction paradigms.

Additional Key Words and Phrases: artifact ecologies, communicative ecologies, device ecologies, information ecologies, theory

\section{ACM Reference Format:}

Peter Lyle, Henrik Korsgaard, and Susanne Bødker. 2020. What's in an Ecology? A Review of Artifact, Communicative, Device and Information Ecologies. In Proceedings of the 11th Nordic Conference on Human-Computer Interaction: Shaping Experiences, Shaping Society (NordiCHI '20), October 25-29, 2020, Tallinn, Estonia. ACM, New York, NY, USA, 21 pages. https://doi.org/10.1145/3419249.3420185

\section{INTRODUCTION}

Human-computer interaction is rarely about interacting with a single device or software in isolation. It entails switching between multiple devices and applications, and increasingly individual devices are, and can be understood as, interfaces to complexes or networks of software systems running on a myriad of different hardware configurations in data centers, or on devices within the local area network. Even more so, human-computer interaction happens in the context of other artifacts and resources within a particular environment. Across four decades, multiple works have adopted or developed different ecological theories and metaphors to try to make sense of, conceptualise and theorise on the above. The tone and focus in the early work from the 1980s and 90s, e.g. Capurro [28], Harris [52], Kling and Scacchi [73] and, Star and Ruhleder [123], is on bringing attention to the multiplicity of artifacts and ecological perspectives, arguing for more holistic and cultural dimensions and establishing a useful vocabulary. In parallel, several technological visions were proposed, with Weiser's [92] vision of the computer for the 21st century being the most prominent. This spawned significant interest in making ecologies an object of design, focusing on ubiquitous and context-aware computing, and later cross-device interaction and internet of things. As multiple devices, software applications and networked services have become more common, empirical work has taken these constellations as an object of study [e.g. 10, 67, 116].

Permission to make digital or hard copies of all or part of this work for personal or classroom use is granted without fee provided that copies are not made or distributed for profit or commercial advantage and that copies bear this notice and the full citation on the first page. Copyrights for components of this work owned by others than the author(s) must be honored. Abstracting with credit is permitted. To copy otherwise, or republish, to post on servers or to redistribute to lists, requires prior specific permission and/or a fee. Request permissions from permissions@acm.org.

(c) 2020 Copyright held by the owner/author(s). Publication rights licensed to ACM.

Manuscript submitted to ACM 
Extensive work has been done to explore models and interaction techniques that support cross device interaction [e.g. $56,57,93$ ] (see also Brudy et al.'s survey of cross-device interaction [27]).

When examining these efforts, a complex landscape of concepts and terms emerge, that span multiple understandings, theoretical underpinnings, foci, implications and approaches. Empirical, theoretical and design-oriented work has proposed personal artifact ecologies, technology assemblages, communicative ecologies, cultural ecologies, information ecologies, hybrid ecologies, cross device ecologies, ubiquitous computing ecologies, just to name a few (see tables 2, 3, 4, 5 for a complete list). Much of this work proposes and develops a specific concept but does little to connect with other work systematically. For instance, Rossitto et al.'s work on constellations of technologies [116] only briefly mentions other works on artifact ecologies [17]. Bødker et al.'s work on community artifact ecologies [20] expands on Jung et al.'s concept of personal artifact ecologies [67] , but refrains from discussing other concepts extensively. Tchounikine [128] discusses various definitions of ecologies of artifacts but makes distinction between instrumental clusters of artifacts, and collective work activities as two different approaches to such ecologies. Raptis et al.'s work on digital ecologies [110] is an attempt to integrate a subset of the concepts discussed in literature. Turner [133] discusses different perspectives on information and artifact ecologies to provide a broader understanding of everyday life with technology. Recent work of Brundy et al. [27] surveys multi-surface interaction, With a corpus that is larger than ours, they reflect on their terminology, similarly to what we set out to achieve with the current paper.

Our starting point is that the multiple perspectives and their parallel genealogies create a somewhat blurred image of how HCI conceptualizes, studies, and designs for collections of artifacts. Our thesis is that commonalities and differences across the proposed concepts need to be understood better for the benefit of the research community: Not only is it possible to cluster the existing works into fewer concepts without losing the explanatory strength and consistency across the body of work; cross-fertilization has the potential of enriching the concepts and invite new ways to study, theorize and design for ecologies of artifacts. Our contribution is threefold: First, we present a survey of the existing concepts and draw out important distinctions between different kinds of research and roles of theory. Secondly we synthesize concepts as to propose a simple clustering into four categories. Third, we then discuss these distinctions and how they might enrich the understanding across analytical levels, and crosscutting themes. The structure of the paper reflects this, following from our review method, and concludes with a discussion on the lack of connections and state of theorising.

\section{REVIEW METHODOLOGY}

The review approach follows the semi-systematic and integrative review approaches discussed by Snyder [121]. The reviewed literature was collected with departure in sources familiar to the authors, e.g. works on information ecologies [101], artifact ecologies [17, 67], communicative ecologies [45] and cross device research [56]. From there we expanded the corpus by (a) examining works that cite, or are cited-by, publications in the corpus, and (b) identifying concepts, e.g. technology assemblages or service ecologies in the expanding corpus, and searching for these on Google Scholar and the ACM Digital Library. This was done iteratively as the list of publications and concepts expanded. We have adopted an inclusive strategy insofar as we include relevant publications and perspectives cited in the key HCI/CSCW/UBICOMPoriented conferences and journals to inform the genealogy of, and theoretical influences in, the survey ${ }^{1}$. The criteria used to determine whether to stop the recursive search were as follows: 1) does the paper clearly address technology (e.g. infrastructure, artifacts, devices)? 2) does the paper address technology in use (e.g. the interaction between the

\footnotetext{
${ }^{1}$ Four publications cited in the primary literature were unavailable to us at the time of writing and have been excluded from the survey.
} 


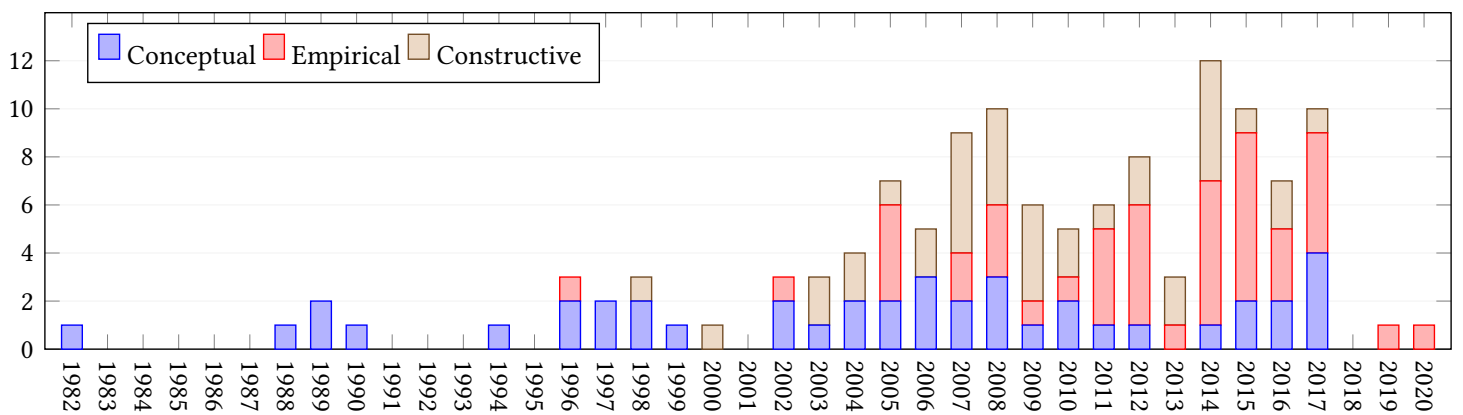

Fig. 1. Publications per year for each research type: Constructive-, empirical, and conceptual research (see section 3)

technology and people, or the utility/functionality of technology is discussed)? And 3) Is the focus of the paper relevant to the wider fields of $\mathrm{HCI} / \mathrm{CSCW} / \mathrm{UBICOMP}$ (e.g. we would ignore papers that focus heavily on knowledge management, human resources and management disciplines).

We have excluded papers that study or discuss application of technology within ecological research [e.g. 7, 69], works that apply ecological psychology [e.g. 47] in (interface) design [e.g. 51, 111, 139], or positions that discuss more generic perspectives within research (sub) areas such as smart environments, ambient intelligence, internet of things, etc. Further, we have chosen not to include thesis work as the identified theses are paper-based formats, hence the discussion in the theses mirror those in the included papers [e.g. 74, 75, 94]. We have included works that explicitly focus on, or discuss, an ecological perspective in the work, or works that build upon existing work within that definition. Several of the publications have been published outside the main HCI and CSCW venues and many intermediate discussions has happened in workshop contributions [e.g. 14, 58] and elsewhere [e.g. 141]. The final list includes 129 publications and 54 identified concepts. Since the first identified publication, Kling and Scacchi [73], 54 different concepts have been proposed and worked on in HCI and CSCW research. Figure 1 highlights the distribution of the work and an increased interest in the topic since the early 2000 s.

\section{ANALYSIS: RESEARCH TYPES AND THE ROLE OF THEORY}

In the review we want to examine the conceptual and theoretical developments across the corpus. First, we examine the different types of research based on Oulasvirta and Hornbæk's [104] adoption of Laudan's discussion on different types of research problems and solutions. Second, we categorize the publications according to how (if) they apply the concepts and the role theory play in the work. Here we combine different perspective on the role of theory in HCI [e.g. $50,68,115]$ to try to make sense of the state of the concepts and of how theory is positioned in the works.

\subsection{Research types}

Categorizing the different genres of research allows us to identify the multiplicity of approaches informing the conceptual developments across the corpus and points to ways in which combinations of research types can further develop the concepts. Oulasvirta and Hornbæk present three categories of research types within HCI: empirical research that aims at creating or elaborating descriptions of real-world phenomena related to human use of computing; conceptual research that aims at explaining previously unconnected phenomena occurring in interaction; and constructive research that producing understanding about the construction of an interactive artefact for some purpose in human use of computing [104, p. 4958]. Further, they observe how HCI often mixes problem types, e.g. design work that takes inspiration from 


\begin{tabular}{|c|c|c|c|c|}
\hline Research types & Descriptive & Applied & Analysis & Synthesis \\
\hline $\begin{array}{l}\text { Empirical } \\
29 \text { publications }\end{array}$ & $\begin{array}{l}{[89,101,102,109,135,} \\
145]\end{array}$ & $\begin{array}{l}{[9,33,38,39,48,65,90,95} \\
118,130,136,137]\end{array}$ & $\begin{array}{l}{[20,21,46,66,82,97,134,} \\
138,146]\end{array}$ & {$[44,63]$} \\
\hline $\begin{array}{l}\text { Empirical - Conceptual } \\
25 \text { publications }\end{array}$ & {$[25,64,99,123,126]$} & {$[10,54,55,62,140]$} & $\begin{array}{l}{[5,12,17,19,32,70,100} \\
103,116,119,124,149]\end{array}$ & {$[22,67,73,80]$} \\
\hline $\begin{array}{l}\text { Conceptual } \\
22 \text { publications }\end{array}$ & $\begin{array}{l}{[4,24,26,52,53,58,125,} \\
127,132]\end{array}$ & {$[107]$} & $\begin{array}{l}{[2,18,28,77,78,128,133,} \\
144]\end{array}$ & {$[16,71,76,106,131]$} \\
\hline $\begin{array}{l}\text { Conceptual - Constructive } \\
12 \text { publications }\end{array}$ & {$[1,43,56,93,114]$} & {$[11,45,61,120]$} & {$[88,91]$} & {$[110]$} \\
\hline $\begin{array}{l}\text { Constructive } \\
27 \text { publications }\end{array}$ & $\begin{array}{l}{[3,30,83,98,112,113,143,} \\
147]\end{array}$ & $\begin{array}{l}{[6,15,31,40,42,49,57,60} \\
72,79,81,85,87,122,129 \\
142]\end{array}$ & {$[34,86,108]$} & none \\
\hline $\begin{array}{l}\text { Constructive - Empirical } \\
12 \text { publications }\end{array}$ & {$[8,37]$} & {$[13,29,59,117,141,148]$} & {$[35,41,96,105]$} & none \\
\hline
\end{tabular}

Table 1. Corpus of 129 publications clustered by research types and the role of theory in the work.

theoretical concepts developed in or outside HCI; empirical evaluations of prototypes; applying a specific theoretical framing to analyze empirical data, etc. In applying these categorizations analytically, we extend them by making a distinction between work that uses elements of the other categories internally, e.g. evaluating a presented system or proposing concepts local to a specific empirical case, and work that makes an effort in moving from material developed within one category towards one of the other two. Table 1 illustrates the distribution of the work across the three research types and combinations. In line with what [104] found, a majority of the work is focusing purely on empirical and constructive research types, with some work focusing on the conceptual work alone. In terms of theoretical and conceptual development, theorizing from empirical work is far more common than theorizing from constructive work. Work that combines empirical and conceptual types often take inspiration in a concept either in framing the work or directing the empirical focus.

\subsection{The role of theory and concepts}

Contributions apply the ecological framing differently across the corpus. Identifying the different applications and the role theory plays in the publications allow us to pinpoint some of the key theoretical developments and identify cross-cutting concepts. We developed the four theoretical roles from observations across the corpus and with inspiration from $[50,68,115]$. When we use the word 'theory', we assume that at the highest level, the use of ecology or similar can be understood as a theory that frames and positions the work. The four roles theory plays in the corpus are: a descriptive role is when a theory is used to frame the work without further engagement with the theory or concepts; application of theory is when the role is to inform constructive and/or empirical work and the analysis thereof without engaging with the merits or qualities of the theory or concepts themselves; theoretical analysis involves engaging with the a particular theoretical framework with the goal of discussing its qualities and/or developing its inner concepts; and synthesis refers to work that compare and juxtapose multiple theories with the goal of integrating multiple concepts into a unified framework. The categories are intended to convey what the 'ecological' framing do for the work and how the individual publications engage with the theoretical framing. The two former use the theory 'as is', whereas the two latter take on a more generative perspective.

Of the 35 publications use their concept descriptively to position or frame the work, we see a large variation in this category, from work that mentions an ecological concept in passing [e.g. 89], relies on implicit or dictionary definitions 
[e.g. 83] and work that frames a particular empirical or technical focus [e.g. 64, 93, 145], to work that presents a concept in conjunction with other concepts [e.g. 24, 123] or discusses the concept without further development [e.g. 52, 99]. This category reflects the genealogy of the ecological concepts and the movement from acknowledging that various new framings are needed to using a concept to establish a familiar framing for empirical and constructive work. For instance, early works on information ecology $[99,101]$ discuss the concept, whereas the theoretical development happens later [100]. Similarly, technology-oriented work by Rekimoto [112] and later Houben et al. [56] uses this multi-computer and cross-device framing to discuss new research areas without a need for theoretical grounding.

44 of the publications apply different ecological concepts in an applied way, understandably as part of design and empirical analysis. For the empirical work, three perspectives can be observed: First, work that studies an ecology of technologies, e.g. calendars, personal belongings [38, 90]; second, work that examines activities within specific environments and contexts, e.g. hospital ward, meetings, design and learning environments [9, 95, 137, 140]; and third, technologies and use (and non-use [118]) within specific domains and/or activities [e.g. 29, 62, 65]. Similar divisions can be seen within the constructive work, e.g. challenges in designing for a specific kind of ecological concept [e.g. 57, 81, 129], or designing for a particular context [e.g. 49, 141], and use scenarios [e.g. 15, 122], and additionally discussion on the underlying technologies and software models [40, 60, 87, 120]. Common for this work is that the ecological concepts are used to frame and scope the object of study or design. Insights developed pertain to the (use) case study and technologies studied and designed.

38 of the publications engage with their ecological concept analytically, reflecting on and developing the concepts themselves. Several of the influential concepts (see section 4) originate in this work, e.g. information ecologies by Nardi and O'Day [100] or communicative ecologies by Altheide [2]. Several of the positions develop their concepts by applying 'ecology' as a metaphor from biology [e.g. 77, 100], through various applications of existing theories in CSCW/HCI, e.g. Activity Theory [17], Distributed Cognition [138] and semantics [77], or in developing on prior work included in this survey. Another common pattern is to develop the theoretical foundation more thoroughly and cite related concepts, e.g. Bødker et al. [20] considering Nardi and O’Day [100], Krippendorff [76] and Jung et al. [67] in developing their perspective. However, the theoretical and conceptual developments are still self-referential and internal to the works, resulting in concepts that converge on similar topics, concepts and analyses, e.g. Rossitto et al.'s [116] constellations of technologies, Sawyer et al.'s [119] digital assemblages, Jokela et al.'s [66] device ecologies, Bødker et al.'s [20] community artifact ecologies, without being thoroughly developed into a coherent theoretical framing. Similarly, constructive work shows a stronger conceptual commitment to designing and developing technologies from a given ecological perspective, e.g. analysing what device ecologies implies for the underlying software models and design rationale [34, 86].

Finally 12 of the published work go further and explicitly synthesize and/or develop new conceptual dimensions based on previous work. Here we see three different approaches: First, work that develops a full analytical framework. This is present in both the early contributions $[22,73,76]$ and more recent work $[16,67,71]$; second, work that strive to integrate multiple perspectives from related work into useful models and concepts. Here, Jarrahi et al. [63] integrate multiple perspectives in their discussion of artifact ecologies and how different contexts shape the ecologies. LarsenLedet et al. [80] integrate work on artifact ecologies with Rossitto et al.'s [116] work on constellations of technologies and develop concepts for discussing transitions in and across ecologies; and third, work that survey existing work with the aim of integrating multiple elements into an analytical or conceptual model. In their short review Raptis et al. [110] discuss and integrate multiple concepts and propose digital ecologies as an overarching term. Treré and Mattoni [131] categorise four different ecological perspectives based on theory and work within media studies. While offering strong concepts grounded in theory and existing work within the corpus, this work is also underdeveloped from a 


\begin{tabular}{|c|c|c|}
\hline \multicolumn{3}{|r|}{ Information Ecologies } \\
\hline Primary & \multicolumn{2}{|c|}{$\begin{array}{l}\text { Harris [52] (1989); Capurro [28] (1990); Nardi and O'day [101] (1996); Hasenyager [53] (1996); Albrechtsen and Jacob [1] } \\
\text { (1997); Nardi [99] (1998); Nardi and O’Day [100] (1999); Baker and Bowker [6] (2007); Finin, Joshi, Kolari, Java, Kale, and } \\
\text { Karandikar [43] (2008); García-Marco [46] (2011); Treré [130] (2012); Johri, Teo, Lo, Dufour, and Schram [65] (2014); } \\
\text { Vasiliou, Ioannou, and Zaphiris [136] (2014); Wang, Guo, Yang, Chen, and Zhang [144] (2017) }\end{array}$} \\
\hline \multirow{10}{*}{ Secondary } & Cultural Ecologies & $\begin{array}{l}\text { Bell [10] (2002); Wakkary and Evernden [141] (2005); Wakkary, Hatala, and Newby [142] } \\
\text { (2006); Cook, Pachler, and Bachmair [33] (2011) }\end{array}$ \\
\hline & Ecology & Turner [133] (2017) \\
\hline & Socio-cultural Ecology & Pachler, Bachmair, and Cook [106] (2010) \\
\hline & Hybrid Cultural Ecology & Lindtner, Nardi, Wang, Mainwaring, Jing, and Liang [82] (2008) \\
\hline & Technologies of Literacy & Bruce and Hogan [26] (1998) \\
\hline & Ecological Perspective & Zhao and Frank [149] (2003) \\
\hline & $\begin{array}{l}\text { Ecology of Ubiquitous Socio-technical } \\
\text { Relations }\end{array}$ & Constantinides and Barrett [32] (2005) \\
\hline & Teaching Learning Ecologies & Bailey and Barley [5] (2011) \\
\hline & Ecology of Infrastructure & Star and Ruhleder [123] (1996) \\
\hline & Web Ecologies & Chi, Pitkow, Mackinlay, Pirolli, Gossweiler, and Card [30] (1998) \\
\hline
\end{tabular}

Table 2. Primary publications use the Information Ecology terminology. Secondary concepts indicate work that is categorized as similar to Information Ecologies.

theoretical perspective, either by offering tentative and incomplete concepts or developing concepts that fit a particular case without considering broader applications.

\section{SYNTHESIS OF INFLUENTIAL CONCEPTS}

Here we provide a deeper introduction to four influential positions - information ecologies, artifact ecologies, device ecologies, and communicative ecologies - selected based on both a higher number of articles that use the concept, and a higher number of other concepts that refer to the influential position (either to differentiate or to build upon). Within these we group the other positions that are either directly related (they are introduced as an extension or in direct connection with existing either the dominant or other minor positions within the same group), or they are trying to achieve a similar goal. Common to all the positions is (1) an interest in relationships between different aspects of what is included in the ecology, and (2) an attempt to take a holistic perspective to understand the particular research context.

\subsection{Information Ecologies}

There are several concepts in which the characteristics of the physical location and the cultural context are core in the ecology, with the most influential (and thus headlining concept) being information ecologies. Information ecologies itself have had multiple strands of development, including Capurro [28], Nardi and O'Day [100] and Albrechtsen and Jacob [1]. As a concept the main development and definition we refer to is from Nardi and O'Day who define it as " $a$ system of people, practices, values, and technologies in a particular local environment. In information ecologies, the spotlight is not on technology, but on human activities that are served by technology" [100].

Another strand of information ecology comes from Baker and Bowker [6], who build on Star and Ruhleder [123] and present the concept as "inclusive of data sets and data collectors, information systems and knowledge makers, as well as digital federations and social networks"[6, p.128]. Garcia-Marco brings these strands together stating "what all these approaches suggest is that the way in which an evolved society manages knowledge transfer is very complex, with many subsystems and logics competing and collaborating, converging and diverging” [46, p. 107]. This quote speaks to understanding being tied to some big picture of a phenomena, going beyond technological artifacts or activities to also include the physical space and cultural practices of a particular context. By placing everything within the scope of 


\begin{tabular}{|c|c|c|}
\hline \multicolumn{3}{|r|}{ Artifact Ecologies } \\
\hline Primary & \multicolumn{2}{|c|}{$\begin{array}{l}\text { Krippendorff [76] (1989); Krippendorff [77] (2006); Vyas and Dix [140] (2007); Jung, Stolterman, Ryan, Thompson, and } \\
\text { Siegel [67] (2008); Krippendorff and Butter [78] (2008); Kirsh [71] (2010); Bødker and Klokmose [16] (2011); Bødker and } \\
\text { Klokmose [17] (2012); Oleksik, Milic-Frayling, and Jones [103] (2012); Sørensen and Kjeldskov [122] (2014); Kjeldskov et al. } \\
\text { [72] (2014); Dittmar and Dardar [38] (2014); Vasiliou, Ioannou, and Zaphiris [137] (2015); Bødker and Klokmose [18] (2015); } \\
\text { Bødker, Korsgaard, and Saad-Sulonen [20] (2016); Bødker, Korsgaard, Lyle, and Saad-Sulonen [19] (2016); Erkut and Serafin } \\
\text { [42] (2016); Bødker, Lyle, and Saad-Sulonen [21] (2017); Jarrahi, Nelson, and Thomson [63] (2017); Vasiliou, Ioannou, } \\
\text { Stylianou-Georgiou, and Zaphiris [135] (2017); Tchounikine [128] (2017); Vasiliou, Ioannou, and Zaphiris [138] (2019); } \\
\text { Larsen-Ledet, Korsgaard, and Bødker [80] (2020) }\end{array}$} \\
\hline \multirow{22}{*}{ Secondary } & Clusters of Artifacts & Bertelsen and Bødker [12] (2002) \\
\hline & Technological Assemblies & $\begin{array}{l}\text { Hindmarsh, Heath, vom Lehn, and Cleverly [54] (2002); Hindmarsh, Heath, Vom Lehn, and } \\
\text { Cleverly [55] (2005) }\end{array}$ \\
\hline & Device Landscapes & Stolterman, Jung, Will, and Siegel [124] (2013) \\
\hline & Web of Technology & Brodersen and Kristensen [25] (2004); Brodersen, Bødker, and Klokmose [24] (2007) \\
\hline & Ecology of Goods & Pantzar [107] (1997) \\
\hline & Web of Computing & Kling and Scacchi [73] (1982) \\
\hline & Digital Assemblages & Sawyer, Crowston, and Wigand [119] (2014) \\
\hline & Product Ecology & Forlizzi [44] (2007) \\
\hline & Product Environment & Margolin [91] (1988) \\
\hline & Personal Information Ecosystems & Tungare, Pyla, Pérez-Quiñones, and Harrison [132] (2006) \\
\hline & Mobile Kits & Mainwaring, Anderson, and Chang [90] (2005); Oulasvirta and Sumari [105] (2007) \\
\hline & Multi-Display Environment & Biehl, Baker, Bailey, Tan, Inkpen, and Czerwinski [13] (2008) \\
\hline & Ecology of Devices & Rick [114] (2009) \\
\hline & Ecology of Tools & Balakrishnan, Matthews, and Moran [8] (2010) \\
\hline & Technology Ecology & Chu and Quek [31] (2013) \\
\hline & Technology Assemblages & Jarrahi [62] (2014) \\
\hline & Constellation of Technologies & Rossitto, Bogdan, and Severinson-Eklundh [116] (2014) \\
\hline & Flexible Ecologies & Luff, Yamashita, Kuzuoka, and Heath [89] (2015) \\
\hline & Personal Ecology & Dittmar and Dardar [39] (2015) \\
\hline & Web of Artifacts & Bossen [22] (2002); Bardram and Bossen [9] (2005) \\
\hline & Device Ecology* & Coughlan, Collins, Adams, Rogers, Haya, and Martín [34] (2012) \\
\hline & Device Ensembles* & Sambasivan, Ventä, Mäntyjärvi, Isomursu, and Häkkilä [118] (2009) \\
\hline
\end{tabular}

Table 3. Primary publications use the Artifact Ecology terminology. Secondary concepts indicate work that is categorized as similar to Artifact Ecologies. Concepts marked* indicate a terminological overlap with concepts in Device Ecologies (see table 4)

the information ecology, it is not surprising that some of these concepts (e.g. technologies of literacy [26], ecology of ubiquitous socio-technical relations [32], and ecology of infrastructure [123]) refer to the field of STS.

This interest in the lived and experienced environment is also seen in cultural ecologies, where Bell [10] speaks to the background of cultural ecology as coming from the 1960s and being interested in the co-evolution of culture and the lived environment. Other relatively minor concepts within this space also include Turner [133], while discussing information ecologies and other ecology work used to understand people, practices and stuff, takes a similarly big picture while connecting with different philosophical and psychological concepts; and socio-cultural ecology by Pachler et al. [106] which argues, in the case of mobile learning, against activity theory for addressing a socio-cultural ecology where the agency of people, their cultural practices and social structures are dominant conceptual aspects.

Examples of use of these types of concepts include libraries [46, 100], an intensive care unit of a hospital [100], a self-service copy shop Nardi and O’Day [100], museums [10], teaching and learning settings [106, 149], and long term research projects [6].

\subsection{Artifact Ecologies}

While the origin of the term seems to come from Krippendorff [76] as ecology of artifacts, as an influential concept for our purposes, the more common term seems to be artifact ecologies, which has undergone conceptual development 
along two strands, one starting from Jung et al. [67]. This has been more widely adopted and built upon for further development of artifact ecologies, as discussed here, and for the development of other concepts, e.g. Device Landscapes [124], as well as some of the work on device ecologies presented in the next section [57].

The common interest among artifact ecology and similar concepts is on foregrounding the relationships of artifacts to practices (both what they are, and how both change), in the context of individual persons or groups of people. As such, it seems less common (compared with information ecologies) that people are necessarily included as part of the ecology. While there is an interest in the multiplicity of people, stuff and activities, the foreground tends towards the activity shaped by the artifacts, as opposed to the cultural and big-picture dimensions of information ecologies.

The dominant strand of use of the term artifact ecologies as it has arisen from the work of Jung et al. [67] began with an initial focus on the personal ownership and use of different artifacts as part of daily practice. Here Jung et al. [67] define a personal ecology of interactive artifacts as " $a$ set of all physical artifacts with some level of interactivity enabled by digital technology that a person owns, has access to, and uses" [67, p. 201] and include a mix of qualitative methods, including visual mapping, which has been built on by Bødker et al. [21]. Theoretical work that has built on this to ground artifact ecologies within activity theory includes the Human-Artifact Model [16], articulating the dialectical way in which the ecology-at-large changes [17].

In contrast to the activity theoretical grounding of the first strand, Vyas and Dix [140] briefly distinguish their unrelated strand of artefact ecologies from activity theory (as well as other theories such as distributed cognition and struturation theory), based on what they suggest is a common "lack of support for embodiment and materiality" [140, p.5]. Enquist et al. [41] defined an ecology based on its functional role: "functional set of artifacts, people and the surrounding environment, in combination with the rich interaction between people and devices we identify as an 'interaction ecology"' [41, p.9 ]. Examples of where artifact ecology concepts have been applied include understanding personal ownership and use [63, 67, 90, 105], and groups of people (e.g. local communities [20] or research collaborators [103]), the intersection between [21], or in specific activity domains, such as personal calendar management [38, 39] or collaborative writing [80]. The concept has been used with a basis in activity theory [16] and more recently with distributed cognition [136].

\subsection{Device Ecologies}

To contrast with the focus on culture, place, activities and people of the previous two influential concepts, device ecologies instead put the devices, how they are connected and how we can understand the workflow across devices, at the forefront. It is understandably the closest of the influential concepts to the field of ubiquitious computing, and is also related to cross-device interaction research (see [27]). We see device ecologies defined by Loke [85, pp. 559-560] as: "consisting of devices (in the environment and on users) interacting synergistically with one another, with users, and with Internet resources, undergirded by appropriate software and communication infrastructures that range from Internet-scale to very short range wireless networks". This work has been referenced by other authors including Bellucci et al. [11], Coughlan et al. [34] within device ecologies, and, for example, Chu and Quek [31], Vasiliou et al. [136] regarding other concepts.

Ryan et al. [117] introduce device ecology as being built on the framework of previous artifact ecology work [67]. Their work is mainly referenced by members of the same research group in relation to other concepts, as well as other artifact ecology work. Ultimately this strand seems fairly minor but speaks to overlaps between what device and artifact ecologies seek to achieve. Finally, there is work by Houben et al. [57], which also builds on Jung et al. [67] while also connecting with activity-theoretical artifact ecology work [16,17]. Houben and colleagues maintain an interest in 


\begin{tabular}{|c|c|c|}
\hline \multicolumn{3}{|r|}{ Device Ecologies } \\
\hline Primary & \multicolumn{2}{|c|}{$\begin{array}{l}\text { Loke [85] (2003); Loke and Ling [86] (2004); Loke, Ling, Butler, and Gillick [87] (2005); Indrawan, Ling, and Loke [60] } \\
\text { (2007); Ryan, Stolterman, Jung, Siegel, Thompson, and Hazlewood [117] (2009); Houben, Tell, and Bardram [57] (2014); } \\
\text { Bellucci, Díaz, Aedo, and Malizia [11] (2013); Mercier [98] (2014); Jokela, Ojala, and Olsson [66] (2015); Houben, Marquardt, } \\
\text { Vermeulen, Klokmose, Schöning, Reiterer, and Holz [56] (2017); Martinez-Maldonado, Goodyear, Kay, Thompson, and } \\
\text { Carvalho [96] (2016); Martinez-Maldonado, Goodyear, Carvalho, Thompson, Hernandez-Leo, Dimitriadis, Prieto, and } \\
\text { Wardak [95] (2017); }\end{array}$} \\
\hline \multirow{11}{*}{ Secondary } & Ambient Ecologies & Goumopoulos and Kameas [49] (2009) \\
\hline & Device Ensembles & Schilit and Sengupta [120] (2004) \\
\hline & Ecologies of Interacting Artifacts & Zaharakis and Kameas [147] (2008) \\
\hline & Digital Ecologies & $\begin{array}{l}\text { Liu, Dyachuk, and Deters [83] (2008a); Wang and Deters [143] (2010); Newon [102] (2011); } \\
\text { Yee, Quek, Endert, Chung, and Sawyer [146] (2012); Raptis, Kjeldskov, Skov, and Paay [110] } \\
\text { (2014); Bagnara and Pozzi [4] (2016) }\end{array}$ \\
\hline & Display Ecosystems/Ecologies & $\begin{array}{l}\text { Terrenghi, Quigley, and Dix [129] (2009); Anzengruber, Castelli, Rosi, Ferscha, and Zam- } \\
\text { bonelli [3] (2013); Huang, Mynatt, and Trimble [59] (2006) }\end{array}$ \\
\hline & Personal Smart Spaces & Papadopoulou, Gallacher, Taylor, and Williams [108] (2012) \\
\hline & Ubiquitous Computing Ecologies & Marquardt [93] (2011); Ledo, Greenberg, Marquardt, and Boring [81] (2015) \\
\hline & Service Ecologies & Dyachuck and Deters [40] (2007) \\
\hline & Multiple-Device Ecology & $\begin{array}{l}\text { Dearman and Pierce [37] (2008); Houben, Vermeulen, Klokmose, Marquardt, Schöning, and } \\
\text { Reiterer [58] (2015); Cecchinato, Cox, and Bird [29] (2017); Blumenstein, Kaltenbrunner, } \\
\text { Seidl, Breban, Thür, and Aigner [15] (2017) }\end{array}$ \\
\hline & Palpable Assemblies & Ingstrup and Hansen [61] (2005) \\
\hline & Interaction Ecologies & Enquist, Tollmar, and Corry [41] (2007) \\
\hline
\end{tabular}

Table 4. Primary publications and secondary concepts categorized as similar to Device Ecologies.

the way in which activities and devices are managed, the different roles that devices take, the way in which technical configuration and connection is between devices is established (both technically and from a usability perspective).

As the interactions between devices is important in understanding and developing device ecologies, it is no surprise that this often involves lab and user studies [57], technical work following business processes [85], and current UbiComp topics e.g. smart homes [49] and proxemics [81].

\subsection{Communicative Ecologies}

Communicative ecologies include work that focuses primarily on communication technologies in relation to practices and communities. Whereas other positions discuss tools used for communication as part of a information ecology or artifact ecology, the following publications take an onset in communication needs or the challenges related to mediating between distributed ecologies, mixing with physical places, and interactions with the digital as mixed realities. In naming the concept, we chose communicative ecology over media or mediating ecologies because of a common reference to Altheid's work on communicative ecologies [2].

The key notion in communicative ecology is that the same technology can be used to for different purposes and evoke different meanings in different contexts [45, p.757]. In order to examine these local appropriations and meanings it is necessary look not only at the communication media, but also include the social interactions and content. Thus, a communicative ecology is defined along three dimensions: a technological, social, and discursive [2, 131].

The concept (including minor positions) has been applied in several ways in the categorized literature: (1) As a technology-centric analyses where studies examine the list of different communication technologies within a particular domain, e.g. the appropriation of communication technologies and social media services within the workplace [64, 134], among students [97], in activism [109] and in a scavenger hunt [48]; (2) with a focus on how (novel) communication 


\begin{tabular}{lll}
\hline \multirow{4}{*}{ Primary } & \multicolumn{1}{c}{ Communicative Ecologies } \\
\hline \multirow{5}{*}{ Secondary } & $\begin{array}{l}\text { Altheide [2] (1994); Tacchi, Slater, and Hearn [127] (2003); Tacchi [126] (2006); Foth and Hearn [45] (2007); Turner, } \\
\text { Qvarfordt, Biehl, Golovchinsky, and Back [134] (2010); Memarovic, Langheinrich, Rubegni, David, and Elhart [97] (2012); } \\
\text { Gonzales, Fiesler, and Bruckman [48] (2015); Treré and Mattoni [131] (2016) }\end{array}$ \\
\cline { 2 - 3 } & Fractured Ecology & Luff, Heath, Kuzuoka, Hindmarsh, Yamazaki, and Oyama [88] (2003) \\
\cline { 2 - 3 } & Sybrid Ecologies & Crabtree and Rodden [35] (2008) \\
\cline { 2 - 3 } & Dual Ecologies & Jarrahi and Sawyer [64] (2012) \\
\cline { 2 - 3 } & Mixed Reality Ecologies & Kuzuoka, Kosaka, Yamazaki, Suga, Yamazaki, Luff, and Heath [79] (2004) \\
\cline { 2 - 3 } & Sew) Media Ecology & Kirk, Crabtree, and Rodden [70] (2005) \\
\cline { 2 - 3 } & Social Media Ecology & Pearson and Trevisan [109] (2015); Treré and Mattoni [131] (2016) \\
\hline
\end{tabular}

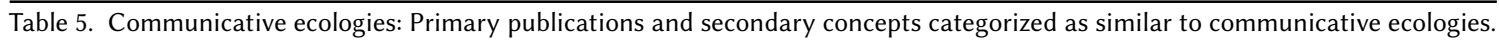

technologies can mediate between multiple locations and distributed actors in collaborative activities, e.g. how collaboration and interactions are mediated by a mixed reality game [35], how novel systems can mediate gestures and bodily interactions between different locales using controllable robots controllable robots $[79,88]$ or video overlays [70]; and (3) within specific communities and analyzing the relationship between social interactions and discourse, and then the mediating technologies, e.g. how complex networks of social relations emerge through online interactions on community boards and social media [45], or a social movement and how they are shaped by all three dimensions of communicative ecologies [131].

\section{THREE LEVELS: MACRO, MESO, MICRO}

The influential concepts above span three conceptual or analytical levels when considering what an ecology is. These levels are useful for understanding the existing work, the kind of foci they takes and the object of interest. We propose that they can also aid future work on ecological perspectives by offering a way to position current and future work, an entry point into the multiple ecological perspectives.

\subsection{Macro: Organisations and activity system(s)}

Several, in particular early works deal with ecologies of tools, practices, people, information, etc. on a macro level. The work frequently seeks to direct attention to the socio-technical process that affects or implicates knowledge work and the role of IT within organisations. Several works from the 1980s and 1990s articulate information ecologies as a primary challenge in organisational knowledge management, for instance. Kling and Scacchi [73] shift perspective from a discrete entity conceptualisation of technology to a networked understanding (web of technologies). Here, a computer system is conceptualised as "an ensemble of equipment, applications, and techniques with identifiable information processing capabilities" [73, p.7]. In their analysis, the authors focus on activities and what people actually do with technology, how they adapt and appropriate technologies to fit local tasks and requirements, and the (invisible) work that is crucial in making IT work ([73, p.18]). The macro level analysis is often connected to and cite Nardi and O'Day's [100] articulation of information ecologies and to some degree Bell's work on museums as cultural ecologies [10], while other work regards the domains of, e.g., organisation [73], knowledge management [28], culture [125] and place [82, 100]. Later work focus on media ecologies within a larger community context and social groups, e.g. activism [109, 131].

These works share commonalities when they approach the vocabulary and analysis from a macro perspective, taking onset in organisations and places. They use cases and examples as arguments for adopting a high-level conceptualisation of the role of technologies in particular practices and domains. Also they tend to position people inside the 'ecology', 
as part of an activity system or as a crucial component in making the information ecology work. For instance, Nardi and O'Day envision an information ecology as “[... ] a richly patterned collaborative system of users, human agents and software agents.” [101, p.86].

\subsection{Meso: People and practices}

A large section of the literature explores and discusses artifact ecologies from the perspective of practices and collaboration. This work varies from examining how larger (urban) communities adopt and negotiate technologies [55], how residents [45] or community groups [21] interact in/through communicative ecologies, web of artifacts in and across work settings, e.g. disperse physical plants, [12], research [123] or hospital/medical work [9], and closing in on a micro level analysis, how students negotiate the collaborative tools around academic work [80, 116], or how remote collaborators coordinate [88].

The meso level work spreads over several or the dominant perspectives, in particular artifact and communicative ecologies. At this level practices and collaborations are studied in work as well as in other forms of communities, often in some form of civic setting. Technologies are considered the means used to carry out these practices and often they are looked at as dynamic and changing, and hence influencing the development of the involved practices. Many of these practice-based approaches are not particularly concerned with building up a theoretical or conceptual foundation, often due to their ethnomethodological inklings. Some of them, however have been important for the development of the perspectives of infrastructuring, and others have built on their foundation in Activity Theoretical HCI to build up a conceptual basis, addressing the level of people, practices and technologies together.

\subsection{Micro: Individuals, artifacts and tasks}

In addition to these two levels, some work in the survey has a conceptual focus on atomic aspects of an ecology, in particular we have found a number of papers with a focus on individual people or individual artifacts, or for that matter particular activities or tasks. Each analytical 'anchoring point' develops from a few key papers: The focus on the individual develops from Mainwaring et al. [90] and Jung et al. [67]; the focus on the artifact develops from works within design theory, primarily Krippendorff [76]; and less researched, task-centered focus, e.g. Bouvin et al.’s [23] detailed comparison of technologies for map use.

It is relevant to highlight here the work of Bødker and Klokmose [16] and in particular [17] on the Human-Artifact Model (as part of developing artifact ecologies grounded in Activity Theory), which provides a means through which to look at both individual people and individual artifacts as foci within an ecology. Bødker and Klokmose [17] and [18] focus on the role of smart phones in shifting the personal artifact ecology of their users. In this manner this particular analysis is an example of an analysis that concerns both a particular person and a particular device/artifact. The personal artifact, as part of an artifact ecology is the starting point of [67] as well as of later examples of calendars by Dittmar and Dardar [38, 39]. Particular artifacts are in focus in much recent work on cross-device interaction, hence device ecologies, e.g. $[58,81]$ where the conceptual work is aiming to understand how artifacts move or are distributed across devices, depending often on the needs arising from specific forms of collaboration or movement of the activity. Even at this level, the conceptual build-up between cases and papers is quite week, again with the exception of Activity Theory based papers. 


\subsection{Levels in summary}

We have seen some connection between levels of analysis and dominating perspective, yet as with the perspectives, these levels are not very well conceptualized in the work for the most part. Publications tend to be implicit about the analytical scope of the work, suggesting that the presented concepts operate on multiple levels. Key challenges in moving forward is research that explicitly targets each level, further defining the upper and lower bounds, and the appropriate empirical and analytical tools, and design interventions; and subsequently connects the three levels with sufficient theoretical and socio-technical quality. As it is now, empirical and conceptual work is 'over represented' at the macro and meso level, while constructive work dominate the macro level (see e.g. [27]).

\section{CROSS-CUTTING THEMES AND PERSPECTIVES}

Here we reflect on themes that cut across the major and minor concepts, primarily developed from works has a conceptual element and analyse and synthesise concepts (see table 1). This serves both as a guide to the existing work on ecological concepts and suggests future directions for work on ecological concept HCI research.

\subsection{Collections of technologies}

Ecological concept research within HCI takes a number of different positions on what is in an ecology concerning tools or technologies, both in the present sense of what is here now, as well as the historical development and hypothetical future (design more generally). Several challenges emerge when works make decisions on what to include in an ecology concept: First, regardless if the ecology is defined by people and technologies, as belonging to organisations, communities or individuals, or by being present in a given context, the analysis typically lets the object of study and/or design be the deciding factor. This frequently turns in to naively 'doing inventory' or a narrow technological focus. Second, a majority of the work focuses on computational technologies, often giving them a prominent position over non-computational artifacts. Very few publications reflect on this dichotomy or the implications for what is studied and designed. As Bødker and Klokmose point out, making unwarranted distinctions between the 'physical' and 'digital' is not fruitful [p.3 18]. While perhaps beneficial in setting the stage and focus for a study or prototype, it limits the conceptualisations and nuanced understanding of what an ecology concept describes.

A few positions discuss nuances on what is in the ecology based on functional and situational needs: Oulasvirta and Sumari [105] make a few useful distinctions between the active subset, the artifacts (devices and non-computational support) in momentary use, and the passive subset, those physically available, but not currently used. Similarly, Rossitto et al. [116] and Larsen-Ledet et al. [80] discuss the aligned part of the ecology as the tools agreed upon among collaborators and the potential part of the ecology as those familiar and available to the sum of collaborators, if needed. These distinctions describe the detailed dynamics of ecologies and provide useful analytical concepts to be further developed. By contrast communicative ecologies focus entirely on technology that serves the purpose of communication, while also not distinguishing between physical and digital [2].

\subsection{Boundaries and contexts}

Related to the conception of tools and technology above there is, in the works, a more general sense of where an ecology is anchored and where it draws its bounds. For instance, Bødker et al. [20] use the community studied as the bounds of the ecology, while also including (but distinguishing) the external events and factors (e.g. device rental costs, or regulatory requirements) that lead to different technology design and use. Mainwaring et al. [90] and Jung et al. [67] by 
contrast focus on individuals as the bounds of the ecology. Other examples include particular settings, e.g. meeting spaces [140], libraries [101], apartment blocks [45] and classrooms [136]. Finally, Krippendorff [76] and Forlizzi [44] put the artifact in the centre and examine these through its various contexts.

What is within the ecology is negotiated, roughly speaking, between what is there, what users are familiar with, and what is needed $[25,105,116]$. These negotiations also happen at the boundaries between different ecologies. Rossitto et al. [116] describe how students negotiate tools both in advance and when needs arise. Bødker et al. [20] describe how a community's ecology originate in the founding members personal ecologies. Throughout the lifecycle of the community, these are further negotiated as responses to external and internal events [19]. Larsen-Ledet et al. [80] draw on the above work and propose a model for examining the influences from multiple (personal) ecologies, as transitions across multiple personal artifact ecologies, and imply that these may be mechanisms for more permanent integration of new tools into an ecology.

\subsection{State and evolution}

A majority of the publications recognise that ecologies are not static. They change and evolve [16, 19, 100, 132]. This is closely linked with adopting the concept or metaphor from biology and in Nardi and O'Day [100] who note that "[i]nformation ecologies evolve as new ideas, tools, activities, and forms of expertise arise in them" [100]. The notion of development within ecologies is further linked with how new tools are adopted and appropriated [see 128]. The conceptual understanding of change of and in ecologies is significantly underdeveloped, e.g. Oulasvirta and Sumari [105] only examine what is active and passive in use, Enquist et al. [41] see a functioning ecology as a defining trait of an ecology and Sambasivan et al. [118] discuss various scenarios of situated non-use, where certain artifacts are abandoned over time. Tungare et al. [132] discuss evolution and equilibrium as traits of a healthy ecology and how change happens gradually. Bødker and Klokmose [16] develop a state-based model and understanding of the dynamics of artifact ecologies (from the perspective of an individual person). When an ecology no longer fulfills the needs and expectations of the individual, it enters the unsatisfactory state. When a new tool is added it enters an excited state, and when the ecology fulfill the expectations of the user, it is in a stable state. Bødker et al. [19] discuss change over time within a community and their artifact ecology as a mix of happenstance, strategic effort and tactical responses [36] to internal and external circumstances. They show, through a series of models, the different changes within the community artifact ecology and the links to specific internal and external events.

\subsection{Open challenges and future research}

The themes above invite substantial further research. One of the primary challenges is that the concepts that show potential are centered around few publications concentrated on the meso and micro levels, predominantly within work on artifact ecologies (see table 1) and the theoretical foundation informing this work. Instead of identifying concrete research gaps in the existing work, we propose that future research follows a series of expansive steps grounded in the work reviewed here. Foremost, engage with the existing work withing the influential concept and level relevant to the research at hand. The concepts and themes highlighted above are still underdeveloped and rarely applied, analyzed and synthesised into coherent frameworks. For instance, the discussions of active and passive [105], and aligned and potential elements [116] of the ecology need additional empirical and conceptual work before they can inform design and constructive research; second, horizontal moves along the axis of research types, from empirical to constructive and back, could improve and help extend the existing concepts; and third, vertical moves across the three levels, macro, meso and micro, could help integrate the different concepts into more coherent perspectives. 


\section{DISCUSSION AND CONCLUSION}

The rationale for conducting this survey was to read a lot of papers so others do not have to and try to connect ideas and concepts across a body of work that span 129 papers and 54 concepts. The driving thesis has been that while a lot of this work stands isolated and underdeveloped, there must be commonalities and conceptual developments. Our analysis and synthesis indicate that these commonalities can be condensed into four influential positions. We also draw out analytical levels and themes that can inspire application and further developments within the research community. These are the primary contributions of the paper. For the remainder of the paper we highlight and discuss two interconnected issues emerging from the review: The disconnected nature of the corpus and our concern regarding the current state of theorising in $\mathrm{HCI}$ and beyond.

\subsection{Disconnected Work}

When initiating this review we were familiar with multiple diverse works on the topic. Hence, it is no surprise that substantial parts of the corpus stand as somewhat disconnected in terminology, references, research types and genres. However, we have also uncovered underlying cases of 'conceptual carelessness' significantly contributing to the disconnectedness of the concepts.

In the first example different disconnected stands of work apply the same terminology without strong connections between them. Digital ecology is one that has two strands of development, one that leads from [84, 110, 143], another from [95], in addition to multiple works that do not recognise the conceptual origin: [35] use the term as an umbrella term under which their work on Hybrid Ecologies sits, Bagnara and Pozzi [4], Newon [102] use the words descriptively (in [50] terms), and Yee et al. [146] use the term as part of their analysis. Another example is artifact ecologies, originating with Krippendorff [76] as ecology of artifacts, and referenced by Jung et al. [67], but disconnected from Vyas and Dix [140]. Jung et al. [67] drew on multiple perspectives including the information ecologies and were used by Bødker and colleagues [17, 20,21]. Separate to this, Oleksik et al. [103] introduced the term, as a specific type of information ecology.

The second case is where the same group of authors use multiple concepts without distinguishing the difference. Examples of this include: fractured ecologies [88] and the later dual ecologies [79]; or web of technologies [24, 25] and artifact ecologies [16]. Stolterman and colleagues introduce Personal Ecologies of Interactive Artifacts in their 2008 paper based on empirical work where they overlap [67]. A year later they discuss a digitization of their empirical mapping method under the conceptual heading of Device Ecology Mapper and Ecosystems of Interactive Artifacts (and Personal Artifact Ecosystems) without discussing the terminology beyond citing [117, Title \& Fig 1.]. In 2013 they further discuss Device Landscapes [124], again without discussing or bringing between the concepts they have proposed earlier. This includes explaining different concepts using the same figure $\left([124 \text {, Fig 1.] and [124, Fig 1.] })^{2}\right.$.

The last is the more general case of authors introducing a new term or concept, without discussing why previous terms (often mentioned or cited as related work) were insufficient. Some examples of this include constellation of technologies that could probably have just continued to use artifact ecologies and the work would be no less valuable [116]. Different theoretical foundations are used with concept development leading to potential ambiguity that ensues: Bødker and Klokmose [16] establish an Activity Theoretical foundation for artifact ecologies, and later Vasiliou et al. [136] apply Distributed Cognition to the same theory without reflection on the prior theoretical work.

Similar terms ascribed with different meanings, and vice versa, creates more opportunity for fallacies of equivocation and ambiguity within research work. This is distinct from the ways in which concepts develop and evolve over time,

${ }^{2}$ Similar can be observed in work by Dittmar and Dardar, cf. [38, Fig. 3] and [39, Fig. 3] 
where a concept build up more baggage and get pushed in different directions. If there is a rift or division, a split of a concept that may be useful, but having multiple 'minting' of the same words serves more to muddle the research communities understanding. We wish to draw the research communities attention to this, as there is a danger in creating ambiguity in how concepts are defined, introduced, and used. The remedy is first and foremost in the craft of research and academic rigor.

\subsection{Concerns on the current state of theorising}

We are all embedded in our research practices, and we are often working across disciplinary boundaries, drawing concepts, frameworks and theory from a multitude of sources. As such, we understand that engaging in work that misses literature happens, even if supported by a peer review process. While the development, extension and creation of theory is important to build on the foundations of $\mathrm{HCI}$, we recognise there is a certain currency and legitimacy to be earned as researchers by coining something new and exciting, to differentiate ourselves and create a legacy. It seems unclear, and perhaps characteristic to the relative age of the HCI field with regard to theory, how and when contributions to the discourse about 'ecology' concepts warrant a new or expanded name.

While our critique here serves as an attempt to discipline the use of these theoretical concepts within HCI, we do not wish to act as gatekeeper, but rather push the conversation towards a clearer and shared understanding of what these terms refer to, and where they can be useful. If we assume that the body of knowledge reviewed represents a developing body of knowledge that can be synthesised into integrated conceptual and theoretical components over time, then current practices and state of theorising in $\mathrm{HCI}$ raise a few concerns.

Based on the ways in which research is valued in HCI, with a focus on a need to create something novel and exciting, we speculate that a new term serves to emphasise the proposed concept as something different. For researchers not wanting to misinterpret an existing theory or concept, creating a new one is a way to 'hedge ones bets' and avoid diluting or introducing confusion around the existing ones. Based on the number of concepts we have seen, we are not convinced this is effective. A strategy of creating a new concept also serves as a way of trying to distance it from theoretical baggage that surrounds the other concepts. When terms are used in different contexts, or different sub-fields one may also try to avoid confusion by a new concept. For some authors, this may limit the breadth and scope of how they relate to existing work. Given the quantity of research papers and the pace with which the production of new papers moves within $\mathrm{HCI}$, it is understandable that a lot of parallel work is done.

While we have sought to show a rich diversity in work that engages with these terms, and help researchers know the different influential concepts, we have also shown a number of examples of confusion and ambiguity. We conclude with a call for future work to strengthen the capability and vocabulary of the concepts in general. The four influential positions would be a good place to start, if not with some of the other existing concepts. With a plethora of 54 concepts, an argument for a new way to describe and analyse the multiplicity of people, stuff, places, etc. would need to not only engage meaningfully with existing work, but to against existing concepts, lest it muddies the conceptual waters further.

\section{ACKNOWLEDGMENTS}

This project has received funding from the European Research Council (ERC) under the European Union's Horizon 2020 research and innovation programme (grant agreement No 740548). 


\section{REFERENCES}

[1] Hanne Albrechtsen and Elin K Jacob. 1997. Classification systems as boundary objects in diverse information ecologies. Advances in Classification Research Online 8, 1 (1997), 1-18.

[2] David L. Altheide. 1994. An Ecology of Communication: Toward a Mapping of the Effective Environment. The Sociological Quarterly 35, 4 (1994), 665-683. https://doi.org/10.1111/j.1533-8525.1994.tb00422.x

[3] B. Anzengruber, G. Castelli, A. Rosi, A. Ferscha, and F. Zambonelli. 2013. Social Feedback in Display Ecosystems. In 2013 IEEE International Conference on Systems, Man, and Cybernetics. IEEE, 2893-2898.

[4] Sebastiano Bagnara and Simone Pozzi. 2016. The third wave of human computer interaction: From interfaces to digital ecologies. DigitCult-Scientific Journal on Digital Cultures 1, 1 (2016), 59-65.

[5] Diane E. Bailey and Stephen R. Barley. 2011. Teaching-Learning Ecologies: Mapping the Environment to Structure Through Action. Organization Science 22, 1 (2011), 262-285. https://doi.org/10.1287/orsc.1090.0511

[6] Karen S. Baker and Geoffrey C. Bowker. 2007. Information ecology: open system environment for data, memories, and knowing. Journal of Intelligent Information Systems 29, 1 (01 Aug 2007), 127-144. https://doi.org/10.1007/s10844-006-0035-7

[7] Karen S Baker and Florence Millerand. 2016. Infrastructuring ecology: Challenges in achieving data sharing. In Collaboration in the new life sciences. Routledge, 133-160.

[8] Aruna D. Balakrishnan, Tara Matthews, and Thomas P. Moran. 2010. Fitting an Activity-centric System into an Ecology of Workplace Tools. In Proceedings of the SIGCHI Conference on Human Factors in Computing Systems (Atlanta, Georgia, USA) (CHI '10). ACM, New York, NY, USA, 787-790. https://doi.org/10.1145/1753326.1753441

[9] Jakob E. Bardram and Claus Bossen. 2005. A Web of Coordinative Artifacts: Collaborative Work at a Hospital Ward. In Proceedings of the 2005 International ACM SIGGROUP Conference on Supporting Group Work (Sanibel Island, Florida, USA) (GROUP '05). ACM, New York, NY, USA, 168-176. https://doi.org/10.1145/1099203.1099235

[10] Genevieve Bell. 2002. Making sense of museums: The museum as' cultural ecology'. Intel Labs 1 (2002), 1-17.

[11] Andrea Bellucci, Paloma Díaz, Ignacio Aedo, and Alessio Malizia. 2013. Prototyping Device Ecologies: Physical to Digital and Viceversa. In Proceedings of the 8th International Conference on Tangible, Embedded and Embodied Interaction (Munich, Germany) (TEI '14). ACM, New York, NY, USA, 373-376. https://doi.org/10.1145/2540930.2567905

[12] Olav Wedege Bertelsen and Susanne Bødker. 2002. Interaction through clusters of artefacts. European Association of Cognitive Ergonomcs.

[13] Jacob T. Biehl, William T. Baker, Brian P. Bailey, Desney S. Tan, Kori M. Inkpen, and Mary Czerwinski. 2008. Impromptu: A New Interaction Framework for Supporting Collaboration in Multiple Display Environments and Its Field Evaluation for Co-located Software Development. In Proceedings of the SIGCHI Conference on Human Factors in Computing Systems (Florence, Italy) (CHI '08). ACM, New York, NY, USA, 939-948. https://doi.org/10.1145/1357054.1357200

[14] Eli Blevis, Susanne Bødker, John Flach, Jodi Forlizzi, Heekyoung Jung, Victor Kaptelinin, Bonnie Nardi, and Antonio Rizzo. 2015. Ecological Perspectives in HCI: Promise, Problems, and Potential. In Proceedings of the 33rd Annual ACM Conference Extended Abstracts on Human Factors in Computing Systems (Seoul, Republic of Korea) (CHI EA '15). ACM, New York, NY, USA, 2401-2404. https://doi.org/10.1145/2702613.2702634

[15] Kerstin Blumenstein, Martin Kaltenbrunner, Markus Seidl, Laura Breban, Niklas Thür, and Wolfgang Aigner. 2017. Bringing Your Own Device into Multi-device Ecologies: A Technical Concept. In Proceedings of the 2017 ACM International Conference on Interactive Surfaces and Spaces (Brighton, United Kingdom) (ISS '17). ACM, New York, NY, USA, 306-311. https://doi.org/10.1145/3132272.3132279

[16] Susanne Bødker and Clemens Nylandsted Klokmose. 2011. The Human-Artifact Model: An Activity Theoretical Approach to Artifact Ecologies. Human-Computer Interaction 26, 4 (2011), 315-371. https://doi.org/10.1080/07370024.2011.626709

[17] Susanne Bødker and Clemens Nylandsted Klokmose. 2012. Dynamics in Artifact Ecologies. In Proceedings of the 7th Nordic Conference on Human-Computer Interaction: Making Sense Through Design (Copenhagen, Denmark) (NordiCHI '12). ACM, New York, NY, USA, 448-457. https: //doi.org/10.1145/2399016.2399085

[18] Susanne Bødker and Clemens Nylandsted Klokmose. 2015. A dialectical take on artifact ecologies and the physical-digital divide. In Proceedings of the 33rd Annual ACM Conference Extended Abstracts on Human Factors in Computing Systems, ACM, New York. 2401-2404.

[19] Susanne Bødker, Henrik Korsgaard, Peter Lyle, and Joanna Saad-Sulonen. 2016. Happenstance, Strategies and Tactics: Intrinsic Design in a Volunteer-Based Community. In Proceedings of the 9th Nordic Conference on Human-Computer Interaction (Gothenburg, Sweden) (NordiCHI '16). Association for Computing Machinery, New York, NY, USA, Article 10, 10 pages. https://doi.org/10.1145/2971485.2971564

[20] Susanne Bødker, Henrik Korsgaard, and Joanna Saad-Sulonen. 2016. 'A Farmer, a Place and at Least 20 Members': The Development of Artifact Ecologies in Volunteer-based Communities. In Proceedings of the 19th ACM Conference on Computer-Supported Cooperative Work \& Social Computing (San Francisco, California, USA) (CSCW' 16). ACM, New York, NY, USA, 1142-1156. https://doi.org/10.1145/2818048.2820029

[21] Susanne Bødker, Peter Lyle, and Joanna Saad-Sulonen. 2017. Untangling the Mess of Technological Artifacts: Investigating Community Artifact Ecologies. In Proceedings of the 8th International Conference on Communities and Technologies (Troyes, France) (C\&\#38; T '17). ACM, New York, NY, USA, 246-255. https://doi.org/10.1145/3083671.3083675

[22] Claus Bossen. 2002. The Parameters of Common Information Spaces:: The Heterogeneity of Cooperative Work at a Hospital Ward. In Proceedings of the 2002 ACM Conference on Computer Supported Cooperative Work (New Orleans, Louisiana, USA) (CSCW '02). ACM, New York, NY, USA, 176-185. https://doi.org/10.1145/587078.587104 
[23] Niels Olof Bouvin, Christina Brodersen, Susanne Bødker, Allan Hansen, and Clemens Nylandsted Klokmose. 2006. A Comparative Study of Map Use. In CHI '06 Extended Abstracts on Human Factors in Computing Systems (Montréal, Québec, Canada) (CHI EA '06). Association for Computing Machinery, New York, NY, USA, 592-597. https://doi.org/10.1145/1125451.1125575

[24] Christina Brodersen, Susanne Bødker, and Clemens Nylandsted Klokmose. 2007. Ubiquitous Substitution. In Human-Computer Interaction INTERACT 2007, Cécilia Baranauskas, Philippe Palanque, Julio Abascal, and Simone Diniz Junqueira Barbosa (Eds.). Springer Berlin Heidelberg, Berlin, Heidelberg, 179-192.

[25] Christina Brodersen and Jannie Friis Kristensen. 2004. Interaction Through Negotiation. In Proceedings of the Third Nordic Conference on Human-computer Interaction (Tampere, Finland) (NordiCHI '04). ACM, New York, NY, USA, 259-268. https://doi.org/10.1145/1028014.1028054

[26] Bertram C Bruce and Maureen P Hogan. 1998. The disappearance of technology: Toward an ecological model of literacy. Routledge.

[27] Frederik Brudy, Christian Holz, Roman Rädle, Chi-Jui Wu, Steven Houben, Clemens Nylandsted Klokmose, and Nicolai Marquardt. 2019. CrossDevice Taxonomy: Survey, Opportunities and Challenges of Interactions Spanning Across Multiple Devices. In Proceedings of the 2019 CHI Conference on Human Factors in Computing Systems (Glasgow, Scotland Uk) (CHI '19). Association for Computing Machinery, New York, NY, USA, Article 562, 28 pages. https://doi.org/10.1145/3290605.3300792

[28] R Capurro. 1990. Towards an information ecology. Proceedings: Information and quality, definitions and dimensions. London: Taylor Graham. http://www. capurro. de/nordinf. htm (1990), 122-139.

[29] Marta E. Cecchinato, Anna L. Cox, and Jon Bird. 2017. Always On(Line)?: User Experience of Smartwatches and Their Role Within Multi-Device Ecologies. In Proceedings of the 2017 CHI Conference on Human Factors in Computing Systems (Denver, Colorado, USA) (CHI '17). ACM, New York, NY, USA, 3557-3568. https://doi.org/10.1145/3025453.3025538

[30] Ed H Chi, James Pitkow, Jock Mackinlay, Peter Pirolli, Rich Gossweiler, and Stuart K Card. 1998. Visualizing the evolution of web ecologies. In Proceedings of the SIGCHI conference on Human factors in computing systems. ACM Press/Addison-Wesley Publishing Co., 400-407.

[31] Sharon Lynn Chu and Francis Quek. 2013. Information Holodeck: Thinking in Technology Ecologies. In Human-Computer Interaction - INTERACT 2013, Paula Kotzé, Gary Marsden, Gitte Lindgaard, Janet Wesson, and Marco Winckler (Eds.). Springer Berlin Heidelberg, Berlin, Heidelberg, $167-184$.

[32] Panos Constantinides and Michael Barrett. 2005. Approaching Information Infrastructure as an Ecology of Ubiquitous Sociotechnical Relations. In Designing Ubiquitous Information Environments: Socio-Technical Issues and Challenges, Carsten Sørensen, Youngjin Yoo, Kalle Lyytinen, and Janice I. DeGross (Eds.). Springer US, Boston, MA, 249-260.

[33] John Cook, Norbert Pachler, and Ben Bachmair. 2011. Ubiquitous mobility with mobile phones: A cultural ecology for mobile learning. E-learning and Digital Media 8, 3 (2011), 181-195.

[34] Tim Coughlan, Trevor D. Collins, Anne Adams, Yvonne Rogers, Pablo A. Haya, and Estefanía Martín. 2012. The conceptual framing, design and evaluation of device ecologies for collaborative activities. International fournal of Human-Computer Studies 70, 10 (2012), 765 - 779. https: //doi.org/10.1016/j.ijhcs.2012.05.008 Special issue on Developing, Evaluating and Deploying Multi-touch Systems.

[35] Andy Crabtree and Tom Rodden. 2008. Hybrid Ecologies: Understanding Cooperative Interaction in Emerging Physical-digital Environments. Personal Ubiquitous Comput. 12, 7 (Oct. 2008), 481-493. https://doi.org/10.1007/s00779-007-0142-7

[36] Michel de Certeau. 1984. The Practice of Everyday Life. University of California Press.

[37] David Dearman and Jeffery S. Pierce. 2008. It's on My Other Computer!: Computing with Multiple Devices. In Proceedings of the SIGCHI Conference on Human Factors in Computing Systems (Florence, Italy) (CHI '08). ACM, New York, NY, USA, 767-776. https://doi.org/10.1145/1357054.1357177

[38] Anke Dittmar and Laura Dardar. 2014. Studying Ecologies of Calendar Artifacts. In Proceedings of the 2014 European Conference on Cognitive Ergonomics (Vienna, Austria) (ECCE '14). ACM, New York, NY, USA, Article 5, 8 pages. https://doi.org/10.1145/2637248.2637267

[39] Anke Dittmar and Laura Dardar. 2015. Personal ecologies of calendar artifacts. Fournal of Interaction Science 3, 1 (28 Jul 2015), 2. https: //doi.org/10.1186/s40166-015-0007-x

[40] D. Dyachuck and R. Deters. 2007. The Impact of Transient Loads on the Performance of Service Ecologies. In 2007 Inaugural IEEE-IES Digital EcoSystems and Technologies Conference. 245-250. https://doi.org/10.1109/DEST.2007.371978

[41] Henrik Enquist, Konrad Tollmar, and Aino Vonge Corry. 2007. Interaction Ecologies. Designing for Palpability Workshop on Pervasive computing (2007).

[42] Cumhur Erkut and Stefania Serafin. 2016. From Ecological Sounding Artifacts Towards Sonic Artifact Ecologies. In Proceedings of the 2016 CHI Conference Extended Abstracts on Human Factors in Computing Systems (San Jose, California, USA) (CHI EA '16). ACM, New York, NY, USA, 560-570. https://doi.org/10.1145/2851581.2892583

[43] Tim Finin, Anupam Joshi, Pranam Kolari, Akshay Java, Anubhav Kale, and Amit Karandikar. 2008. The Information Ecology of Social Media and Online Communities. AI Magazine 29, 3 (Sep. 2008), 77. https://doi.org/10.1609/aimag.v29i3.2158

[44] Jodi Forlizzi. 2007. How Robotic Products Become Social Products: An Ethnographic Study of Cleaning in the Home. In Proceedings of the ACM/IEEE International Conference on Human-robot Interaction (Arlington, Virginia, USA) (HRI '07). ACM, New York, NY, USA, 129-136. https: //doi.org/10.1145/1228716.1228734

[45] Marcus Foth and Greg Hearn. 2007. Networked Individualism of Urban Residents: Discovering the communicative ecology in inner-city apartment buildings. Information, Communication \& Society 10, 5 (2007), 749-772. https://doi.org/10.1080/13691180701658095

[46] Francisco-Javier García-Marco. 2011. Libraries in the digital ecology: reflections and trends. The electronic library 29, 1 (2011), 105-120.

[47] James J Gibson. 2014. The ecological approach to visual perception: classic edition. Psychology Press. 
[48] Joseph A. Gonzales, Casey Fiesler, and Amy Bruckman. 2015. Towards an Appropriable CSCW Tool Ecology: Lessons from the Greatest International Scavenger Hunt the World Has Ever Seen. In Proceedings of the 18th ACM Conference on Computer Supported Cooperative Work \&\#38; Social Computing (Vancouver, BC, Canada) (CSCW'15). ACM, New York, NY, USA, 946-957. https://doi.org/10.1145/2675133.2675240

[49] Christos Goumopoulos and Achilles Kameas. 2009. Ambient ecologies in smart homes. The computer journal 52, 8 (2009), 922-937.

[50] Christine A. Halverson. 2002. Activity Theory and Distributed Cognition: Or What Does CSCW Need to DO with Theories? Computer Supported Cooperative Work (CSCW) 11, 1 (01 Mar 2002), 243-267. https://doi.org/10.1023/A:1015298005381

[51] Peter A Hancock, John M Flach, Jeff Caird, and Kim J Vicente. 2018. Local applications of the ecological approach to human-machine systems. CRC Press.

[52] K. Harris. 1989. Short Report: Information Ecology. Int. J. Inf. Manag. 9, 4 (Dec. 1989), 289-290. https://doi.org/10.1016/0268-4012(89)90052-2

[53] Bruce W Hasenyager. 1996. Managing the information ecology: A collaborative approach to information technology management. Greenwood Publishing Group.

[54] Jon Hindmarsh, Christian Heath, Dirk vom Lehn, and Jason Cleverly. 2002. Creating Assemblies: Aboard the Ghost Ship. In Proceedings of the 2002 ACM Conference on Computer Supported Cooperative Work (New Orleans, Louisiana, USA) (CSCW '02). Association for Computing Machinery, New York, NY, USA, 156-165. https://doi.org/10.1145/587078.587101

[55] Jon Hindmarsh, Christian Heath, Dirk Vom Lehn, and Jason Cleverly. 2005. Creating assemblies in public environments: Social interaction, interactive exhibits and CSCW. Computer Supported Cooperative Work (CSCW) 14, 1 (2005), 1-41.

[56] Steven Houben, Nicolai Marquardt, Jo Vermeulen, Clemens Klokmose, Johannes Schöning, Harald Reiterer, and Christian Holz. 2017. Opportunities and Challenges for Cross-device Interactions in the Wild. interactions 24, 5 (Aug. 2017), 58-63. https://doi.org/10.1145/3121348

[57] Steven Houben, Paolo Tell, and Jakob E. Bardram. 2014. ActivitySpace: Managing Device Ecologies in an Activity-Centric Configuration Space. In Proceedings of the Ninth ACM International Conference on Interactive Tabletops and Surfaces (Dresden, Germany) (ITS '14). ACM, New York, NY, USA, 119-128. https://doi.org/10.1145/2669485.2669493

[58] Steven Houben, Jo Vermeulen, Clemens Klokmose, Nicolai Marquardt, Johannes Schöning, and Harald Reiterer. 2015. Cross-surface: Workshop on interacting with multi-device ecologies in the wild. In Proceedings of the 2015 International Conference on Interactive Tabletops \& Surfaces. ACM, 485-489.

[59] Elaine M. Huang, Elizabeth D. Mynatt, and Jay P. Trimble. 2006. Displays in the Wild: Understanding the Dynamics and Evolution of a Display Ecology. In Pervasive Computing, Kenneth P. Fishkin, Bernt Schiele, Paddy Nixon, and Aaron Quigley (Eds.). Springer Berlin Heidelberg, Berlin, Heidelberg, 321-336.

[60] M. Indrawan, S. Ling, and S. Loke. 2007. Device Ecology: A Micro Digital Ecosystem. In 2007 Inaugural IEEE-IES Digital EcoSystems and Technologies Conference. 192-197. https://doi.org/10.1109/DEST.2007.371969

[61] Mads Ingstrup and Klaus Marius Hansen. 2005. Palpable Assemblies: Dynamic Service Composition in Ubiquitous Computing. In Conference on Software Engineering and Knowledge Engineering. SEKE 2005. Knowledge Systems Institute, 632-638.

[62] Mohammad Hossein Jarrahi. 2014. Examining Practice, Structural, and Interpretive Dimensions of Technology Assemblages: The Case of Social Technology Use by Knowledge Workers. Proceedings of the American Society for Information Science and Technology 51, 1 (2014), 1-10. https://doi.org/10.1002/meet.2014.14505101045

[63] Mohammad Hossein Jarrahi, Sarah Beth Nelson, and Leslie Thomson. 2017. Personal artifact ecologies in the context of mobile knowledge workers. Computers in Human Behavior 75 (2017), 469 - 483. https://doi.org/10.1016/j.chb.2017.05.028

[64] Mohammad Hossein Jarrahi and Steve Sawyer. 2012. Social Networking Technologies and Organizational Knowledge Sharing As a Sociotechnical Ecology. In Proceedings of the ACM 2012 Conference on Computer Supported Cooperative Work Companion (Seattle, Washington, USA) (CSCW '12). ACM, New York, NY, USA, 99-102. https://doi.org/10.1145/2141512.2141552

[65] Aditya Johri, Hon Jie Teo, Jenny Lo, Monique Dufour, and Asta Schram. 2014. Millennial engineers: Digital media and information ecology of engineering students. Computers in Human Behavior 33 (2014), 286-301.

[66] Tero Jokela, Jarno Ojala, and Thomas Olsson. 2015. A Diary Study on Combining Multiple Information Devices in Everyday Activities and Tasks. In Proceedings of the 33rd Annual ACM Conference on Human Factors in Computing Systems (Seoul, Republic of Korea) (CHI '15). ACM, New York, NY, USA, 3903-3912. https://doi.org/10.1145/2702123.2702211

[67] Heekyoung Jung, Erik Stolterman, Will Ryan, Tonya Thompson, and Marty Siegel. 2008. Toward a Framework for Ecologies of Artifacts: How Are Digital Artifacts Interconnected Within a Personal Life? In Proceedings of the 5th Nordic Conference on Human-computer Interaction: Building Bridges (Lund, Sweden) (NordiCHI '08). ACM, New York, NY, USA, 201-210. https://doi.org/10.1145/1463160.1463182

[68] Victor Kaptelinin and Bonnie Nardi. 2012. Activity theory in HCI: Fundamentals and reflections. Synthesis Lectures Human-Centered Informatics 5 , 1 (2012), 1-105.

[69] H. Karasti and K. S. Baker. 2004. Infrastructuring for the long-term: ecological information management. In 37th Annual Hawaii International Conference on System Sciences, 2004. Proceedings of the. 10 pp.--

[70] David Kirk, Andy Crabtree, and Tom Rodden. 2005. Ways of the Hands. In ECSCW 2005, Hans Gellersen, Kjeld Schmidt, Michel Beaudouin-Lafon, and Wendy Mackay (Eds.). Springer Netherlands, Dordrecht, 1-21.

[71] David Kirsh. 2010. Explaining Artifact Evolution. In Cognitive Life of Things: Recasting the Boundaries of the Mind, L. Malafouris (Ed.). Cambridge Univ. Press. 
[72] Jesper Kjeldskov et al. 2014. Concepts of multi-artifact systems in artifact ecologies. In 7th International Conference on Advances in Computer-Human Interactions, ACHI 2014. International Academy, Research, and Industry Association (IARIA), 141-146.

[73] Rob Kling and Walt Scacchi. 1982. The Web of Computing: Computer Technology as Social Organization. Advances in Computers, Vol. 21. Elsevier, 1 - 90. https://doi.org/10.1016/S0065-2458(08)60567-7

[74] Clemens Nylandsted Klokmose. 2009. On Human-Computer Interaction in Complex Artefact Ecologies. Ph.D. Dissertation.

[75] Henrik Korsgaard. 2016. Toward Place-Centric Computing: Making Place With Technology Together. Ph.D. Dissertation.

[76] Klaus Krippendorff. 1989. On the essential contexts of artifacts or on the proposition that" design is making sense (of things)". Design issues 5, 2 (1989), 9-39.

[77] Klaus Krippendorff. 2006. The semantic turn: A new foundation for design. ARTIFACT-ROUTLEDGE- 1, 11 (2006), 51.

[78] Klaus Krippendorff and Reinhart Butter. 2008. SEMANTICS: MEANINGS AND CONTEXTS OF ARTIFACTS11. In Product Experience, Hendrik N.J. Schifferstein and Paul Hekkert (Eds.). Elsevier, San Diego, 353 - 376. https://doi.org/10.1016/B978-008045089-6.50017-4

[79] Hideaki Kuzuoka, Jun'ichi Kosaka, Keiichi Yamazaki, Yasuko Suga, Akiko Yamazaki, Paul Luff, and Christian Heath. 2004. Mediating Dual Ecologies. In Proceedings of the 2004 ACM Conference on Computer Supported Cooperative Work (Chicago, Illinois, USA) (CSCW '04). ACM, New York, NY, USA, 477-486. https://doi.org/10.1145/1031607.1031686

[80] Ida Larsen-Ledet, Henrik Korsgaard, and Susanne Bødker. 2020. Collaborative Writing Across Multiple Artifact Ecologies. In Chi'20: Proceedings of the 2020 Chi Conference on Human Factors in Computing Systems. ACM Digital Library.

[81] David Ledo, Saul Greenberg, Nicolai Marquardt, and Sebastian Boring. 2015. Proxemic-Aware Controls: Designing Remote Controls for Ubiquitous Computing Ecologies. In Proceedings of the 17th International Conference on Human-Computer Interaction with Mobile Devices and Services (Copenhagen, Denmark) (MobileHCI '15). ACM, New York, NY, USA, 187-198. https://doi.org/10.1145/2785830.2785871

[82] Silvia Lindtner, Bonnie Nardi, Yang Wang, Scott Mainwaring, He Jing, and Wenjing Liang. 2008. A Hybrid Cultural Ecology: World of Warcraft in China. In Proceedings of the 2008 ACM Conference on Computer Supported Cooperative Work (San Diego, CA, USA) (CSCW '08). ACM, New York, NY, USA, 371-382. https://doi.org/10.1145/1460563.1460624

[83] D. Liu, D. Dyachuk, and R. Deters. 2008. Connecting service ecologies - how to enable external consumers transparent access?. In 2008 2nd IEEE International Conference on Digital Ecosystems and Technologies. 247-253. https://doi.org/10.1109/DEST.2008.4635189

[84] D. Liu, D. Dyachuk, and R. Deters. 2008. Connecting service ecologies - how to enable external consumers transparent access?. In 2008 2nd IEEE International Conference on Digital Ecosystems and Technologies. 247-253.

[85] Seng Wai Loke. 2003. Service-oriented device ecology workflows. In International Conference on Service-Oriented Computing. Springer, 559-574.

[86] Seng Wai Loke and Sea Ling. 2004. Analyzing Observable Behaviours of Device Ecology Workflows.. In ICEIS (4). 78-83.

[87] Seng Wai Loke, Sea Ling, Gerry Butler, and Brett Gillick. 2005. Levels of Abstraction in Programming Device Ecology Workflows.. In ICEIS (4). 137-144.

[88] Paul Luff, Christian Heath, Hideaki Kuzuoka, Jon Hindmarsh, Keiichi Yamazaki, and Shinya Oyama. 2003. Fractured Ecologies: Creating Environments for Collaboration. Human-Computer Interaction 18, 1-2 (2003), 51-84. https://doi.org/10.1207/S15327051HCI1812_3

[89] Paul K. Luff, Naomi Yamashita, Hideaki Kuzuoka, and Christian Heath. 2015. Flexible Ecologies And Incongruent Locations. In Proceedings of the 33rd Annual ACM Conference on Human Factors in Computing Systems (Seoul, Republic of Korea) (CHI '15). ACM, New York, NY, USA, 877-886. https://doi.org/10.1145/2702123.2702286

[90] Scott D. Mainwaring, Ken Anderson, and Michele F. Chang. 2005. Living for the Global City: Mobile Kits, Urban Interfaces, and Ubicomp. In UbiComp 2005: Ubiquitous Computing, Michael Beigl, Stephen Intille, Jun Rekimoto, and Hideyuki Tokuda (Eds.). Springer Berlin Heidelberg, Berlin, Heidelberg, 269-286.

[91] Victor Margolin. 1988. Expanding the Boundaries of Design: The Product Environment and the New User. Design Issues 4, 1/2 (1988), 59-64. http://www.jstor.org/stable/1511388

[92] Weiser Mark. 1991. The computer for the 21st century. Scientific American 265, 3 (1991), 94-104.

[93] Nicolai Marquardt. 2011. Proxemic Interactions in Ubiquitous Computing Ecologies. In CHI '11 Extended Abstracts on Human Factors in Computing Systems (Vancouver, BC, Canada) (CHI EA '11). ACM, New York, NY, USA, 1033-1036. https://doi.org/10.1145/1979742.1979691

[94] Nicolai Marquardt. 2013. Proxemic interactions in ubiquitous computing ecologies. Ph.D. Dissertation. University of Calgary.

[95] Roberto Martinez-Maldonado, Peter Goodyear, Lucila Carvalho, Kate Thompson, Davinia Hernandez-Leo, Yannis Dimitriadis, Luis P Prieto, and Dewa Wardak. 2017. Supporting collaborative design activity in a multi-user digital design ecology. Computers in Human Behavior 71 (2017), 327-342.

[96] Roberto Martinez-Maldonado, Peter Goodyear, Judy Kay, Kate Thompson, and Lucila Carvalho. 2016. An Actionable Approach to Understand Group Experience in Complex, Multi-surface Spaces. In Proceedings of the 2016 CHI Conference on Human Factors in Computing Systems (San Jose, California, USA) (CHI '16). ACM, New York, NY, USA, 2062-2074. https://doi.org/10.1145/2858036.2858213

[97] Nemanja Memarovic, Marc Langheinrich, Elisa Rubegni, Andreia David, and Ivan Elhart. 2012. Designing "Interacting Places" for a Student Community Using a Communicative Ecology Approach. In Proceedings of the 11th International Conference on Mobile and Ubiquitous Multimedia (Ulm, Germany) (MUM '12). ACM, New York, NY, USA, Article 43, 10 pages. https://doi.org/10.1145/2406367.2406420

[98] E. Mercier. 2014. Device ecologies to support collaborative learning in classrooms. In 2014 International Conference on Collaboration Technologies and Systems (CTS). 217-218. https://doi.org/10.1109/CTS.2014.6867567

[99] Bonnie A. Nardi. 1998. Information ecologies. Reference \& User Services Quarterly 38, 1 (Fall 1998), 49-40. 
[100] Bonnie A Nardi and Vicki O’Day. 1999. Information ecologies: Using technology with heart. Mit Press.

[101] Bonnie A Nardi and Vicki O'day. 1996. Intelligent agents: what we learned at the library. Libri 46, 2 (1996), 59-88.

[102] Lisa Newon. 2011. Multimodal creativity and identities of expertise in the digital ecology of a World of Warcraft guild. Digital discourse: Language in the new media 131 (2011).

[103] Gerard Oleksik, Natasa Milic-Frayling, and Rachel Jones. 2012. Beyond Data Sharing: Artifact Ecology of a Collaborative Nanophotonics Research Centre. In Proceedings of the ACM 2012 Conference on Computer Supported Cooperative Work (Seattle, Washington, USA) (CSCW '12). ACM, New York, NY, USA, 1165-1174. https://doi.org/10.1145/2145204.2145376

[104] Antti Oulasvirta and Kasper Hornbæk. 2016. HCI Research As Problem-Solving. In Proceedings of the 2016 CHI Conference on Human Factors in Computing Systems (San Jose, California, USA) (CHI '16). ACM, New York, NY, USA, 4956-4967. https://doi.org/10.1145/2858036.2858283

[105] Antti Oulasvirta and Lauri Sumari. 2007. Mobile Kits and Laptop Trays: Managing Multiple Devices in Mobile Information Work. In Proceedings of the SIGCHI Conference on Human Factors in Computing Systems (San Jose, California, USA) (CHI '07). ACM, New York, NY, USA, 1127-1136. https://doi.org/10.1145/1240624.1240795

[106] Norbert Pachler, Ben Bachmair, and John Cook. 2010. w. Springer US, Boston, MA, 155-171. https://doi.org/10.1007/978-1-4419-0585-7_5

[107] Mika Pantzar. 1997. Domestication of Everyday Life Technology: Dynamic Views on the Social Histories of Artifacts. Design Issues 13, 3 (1997), 52-65. http://www.jstor.org/stable/1511941

[108] Elizabeth Papadopoulou, Sarah Gallacher, Nick K Taylor, and M Howard Williams. 2012. A personal smart space approach to realising ambient ecologies. Pervasive and Mobile Computing 8, 4 (2012), 485-499.

[109] Charlotte Pearson and Filippo Trevisan. 2015. Disability activism in the new media ecology: campaigning strategies in the digital era. Disability \& Society 30, 6 (2015), 924-940. https://doi.org/10.1080/09687599.2015.1051516

[110] Dimitrios Raptis, Jesper Kjeldskov, Mikael B Skov, and Jeni Paay. 2014. What is a digital ecology? Theoretical foundations and a unified definition. Australian fournal of Intelligent Information Processing Systems 13, 4 (2014), 5.

[111] Jens Rasmussen and Kim J. Vicente. 1990. Ecological interfaces: A technological imperative in high-tech systems? International fournal of Human-Computer Interaction 2, 2 (1990), 93-110. https://doi.org/10.1080/10447319009525974

[112] Jun Rekimoto. 2000. Multiple-computer User Interfaces: "Beyond the Desktop" Direct Manipulation Environments. In CHI '00 Extended Abstracts on Human Factors in Computing Systems (The Hague, The Netherlands) (CHI EA '00). ACM, New York, NY, USA, 6-7. https://doi.org/10.1145/633292. 633297

[113] Andrea Resmini and Luca Rosati. 2009. Information architecture for ubiquitous ecologies. In Proceedings of the International Conference on Management of Emergent Digital EcoSystems. ACM, 196-199.

[114] Jochen Rick. 2009. Towards a classroom ecology of devices: Interfaces for collaborative scripts. (June 2009).

[115] Yvonne Rogers. 2012. HCI theory: classical, modern, and contemporary. Synthesis lectures on human-centered informatics 5, 2 (2012), $1-129$.

[116] Chiara Rossitto, Cristian Bogdan, and Kerstin Severinson-Eklundh. 2014. Understanding Constellations of Technologies in Use in a Collaborative Nomadic Setting. Computer Supported Cooperative Work (CSCW) 23, 2 (01 Apr 2014), 137-161. https://doi.org/10.1007/s10606-013-9196-4

[117] William Ryan, Erik Stolterman, Heekyoung Jung, Martin Siegel, Tonya Thompson, and William R. Hazlewood. 2009. Device Ecology Mapper: A Tool for Studying Users' Ecosystems of Interactive Artifacts. In CHI '09 Extended Abstracts on Human Factors in Computing Systems (Boston, MA, USA) (CHI EA '09). ACM, New York, NY, USA, 4327-4332. https://doi.org/10.1145/1520340.1520661

[118] Nithya Sambasivan, Leena Ventä, Jani Mäntyjärvi, Minna Isomursu, and Jonna Häkkilä. 2009. Rhythms of Non-use of Device Ensembles. In CHI '09 Extended Abstracts on Human Factors in Computing Systems (Boston, MA, USA) (CHI EA '09). ACM, New York, NY, USA, 4531-4536. https://doi.org/10.1145/1520340.1520695

[119] Steve Sawyer, Kevin Crowston, and Rolf T. Wigand. 2014. Digital assemblages: evidence and theorising from the computerisation of the US residential real estate industry. New Technology, Work and Employment 29, 1 (2014), 40-56. https://doi.org/10.1111/ntwe.12020

[120] B. N. Schilit and U. Sengupta. 2004. Device ensembles [ubiquitous computing]. Computer 37, 12 (Dec 2004), 56-64. https://doi.org/10.1109/MC. 2004.241

[121] Hannah Snyder. 2019. Literature review as a research methodology: An overview and guidelines. Journal of Business Research 104 (2019), 333 - 339. https://doi.org/10.1016/j.jbusres.2019.07.039

[122] Henrik Sørensen and Jesper Kjeldskov. 2014. Proxemic interactions with multi-artifact systems. Fournal on Advances in Intelligent Systems (2014).

[123] Susan Leigh Star and Karen Ruhleder. 1996. Steps toward an ecology of infrastructure: Design and access for large information spaces. Information systems research 7, 1 (1996), 111-134.

[124] Erik Stolterman, Heekyoung Jung, Ryan Will, and Martin A. Siegel. 2013. Device Landscapes : A New Challenge to Interaction Design and HCI Research. Archives of Design Research 26 (2) (2013), 7-33.

[125] Lance Strate. 2008. Studying media as media: McLuhan and the media ecology approach. (2008).

[126] Jo A. Tacchi. 2006. Studying Communicative Ecologies: An Ethnographic Approach to Information and Communication Technologies (ICTs). (2006). https://eprints.qut.edu.au/4400/

[127] Jo A Tacchi, Don Slater, and Gregory N Hearn. 2003. Ethnographic action research: A user's handbook. Unesco.

[128] Pierre Tchounikine. 2017. Designing for Appropriation: A Theoretical Account. Hum.-Comput. Interact. 32, 4 (July 2017), 155-195. https: //doi.org/10.1080/07370024.2016.1203263 
[129] Lucia Terrenghi, Aaron Quigley, and Alan Dix. 2009. A Taxonomy for and Analysis of Multi-person-display Ecosystems. Personal Ubiquitous Comput. 13, 8 (Nov. 2009), 583-598. https://doi.org/10.1007/s00779-009-0244-5

[130] Emiliano Treré. 2012. Social Movements as Information Ecologies: Exploring the Coevolution of Multiple Internet Technologies for Activism. International fournal of Communication 6, 0 (2012). https://ijoc.org/index.php/ijoc/article/view/1681

[131] Emiliano Treré and Alice Mattoni. 2016. Media ecologies and protest movements: main perspectives and key lessons. Information, Communication \& Society 19, 3 (2016), 290-306. https://doi.org/10.1080/1369118X.2015.1109699

[132] Manas Tungare, Pardha S. Pyla, Manuel Pérez-Quiñones, and Steve Harrison. 2006. Personal Information Ecosystems and Implications for Design. arXiv:cs/0612081 [cs.HC]

[133] Phil Turner. 2017. Everyday Involvement with Technology. Springer International Publishing, Cham, 23-44. https://doi.org/10.1007/978-3-31970653-5_2

[134] Thea Turner, Pernilla Qvarfordt, Jacob T. Biehl, Gene Golovchinsky, and Maribeth Back. 2010. Exploring the Workplace Communication Ecology. In Proceedings of the SIGCHI Conference on Human Factors in Computing Systems (Atlanta, Georgia, USA) (CHI '10). ACM, New York, NY, USA, 841-850. https://doi.org/10.1145/1753326.1753449

[135] Christina Vasiliou, Andri Ioannou, Agni Stylianou-Georgiou, and Panayiotis Zaphiris. 2017. A Glance into Social and Evolutionary Aspects of an Artifact Ecology for Collaborative Learning through the Lens of Distributed Cognition. International fournal of Human-Computer Interaction 33, 8 (2017), 642-654. https://doi.org/10.1080/10447318.2016.1277638

[136] Christina Vasiliou, Andri Ioannou, and Panayiotis Zaphiris. 2014. Understanding collaborative learning activities in an information ecology: A distributed cognition account. Computers in Human Behavior 41 (2014), 544 - 553. https://doi.org/10.1016/j.chb.2014.09.057

[137] Christina Vasiliou, Andri Ioannou, and Panayiotis Zaphiris. 2015. An Artifact Ecology in a Nutshell: A Distributed Cognition Perspective for Collaboration and Coordination. In Human-Computer Interaction - INTERACT 2015, Julio Abascal, Simone Barbosa, Mirko Fetter, Tom Gross, Philippe Palanque, and Marco Winckler (Eds.). Springer International Publishing, Cham, 55-72.

[138] Christina Vasiliou, Andri Ioannou, and Panayiotis Zaphiris. 2019. From behaviour to design: implications for artifact ecologies as shared spaces for design activities. Behaviour \& Information Technology 0, 0 (2019), 1-18. https://doi.org/10.1080/0144929X.2019.1601258

[139] K.J. Vicente and Jens Rasmussen. 1987. Cognitive Control of Human Activities and Errors: Implication for Ecological Interface Design.

[140] Dhaval Vyas and Alan Dix. 2007. Artefact ecologies : supporting embodied meeting practices with distance access. In UbiComp (Ubiquitous Computing) 2007 Workshops, A. Bajart, H.L. Muller, and T. Strang (Eds.). University of Innsbruck, Innsbruck, Austria, 117-122. https://eprints.qut. edu.au/71319/

[141] Ron Wakkary and Dale Evernden. 2005. Museum As Ecology: A Case Study Analysis Of An Ambient Intelligent Museum Guide. In Museums and the Web 2005 Papers. https://www.museumsandtheweb.com/mw2005/papers/wakkary/wakkary.html

[142] Ron Wakkary, Marek Hatala, and Kenneth Newby. 2006. ec (h) o: Ecologies For Designing Playful Interaction. In Designing Effective Communications: Creating Contexts For Clarity And Meaning. Allworth Press, 235-243.

[143] Q. Wang and R. Deters. 2010. Mobile devices, scalability amp;amp; digital ecologies. In 4th IEEE International Conference on Digital Ecosystems and Technologies. 124-129. https://doi.org/10.1109/DEST.2010.5610658

[144] Xiwei Wang, Yu Guo, Mengqing Yang, Yong Chen, and Wenxiao Zhang. 2017. Information ecology research: past, present, and future. Information Technology and Management 18, 1 (01 Mar 2017), 27-39. https://doi.org/10.1007/s10799-015-0219-3

[145] Yiran Wang, Melissa Niiya, Gloria Mark, Stephanie M. Reich, and Mark Warschauer. 2015. Coming of Age (Digitally): An Ecological View of Social Media Use Among College Students. In Proceedings of the 18th ACM Conference on Computer Supported Cooperative Work \&\#38; Social Computing (Vancouver, BC, Canada) (CSCW '15). ACM, New York, NY, USA, 571-582. https://doi.org/10.1145/2675133.2675271

[146] S. L. C. Y. Yee, F. Quek, A. Endert, H. Chung, and B. Sawyer. 2012. The Physicality of Technological Devices in Education: Building a Digital Experience for Learning. In 2012 IEEE 12th International Conference on Advanced Learning Technologies. 579-581. https://doi.org/10.1109/ICALT.2012.151

[147] Ioannis D Zaharakis and Achilles D Kameas. 2008. Engineering Emergent Ecologies of Interacting Artefacts. In Handbook of Research on User Interface Design and Evaluation for Mobile Technology. Igi Global, 364-384.

[148] Xuan Zhao, Cliff Lampe, and Nicole B. Ellison. 2016. The Social Media Ecology: User Perceptions, Strategies and Challenges. In Proceedings of the 2016 CHI Conference on Human Factors in Computing Systems (San Jose, California, USA) (CHI '16). ACM, New York, NY, USA, 89-100. https://doi.org/10.1145/2858036.2858333

[149] Yong Zhao and Kenneth A. Frank. 2003. Factors Affecting Technology Uses in Schools: An Ecological Perspective. American Educational Research fournal 40, 4 (2003), 807-840. https://doi.org/10.3102/00028312040004807 